\title{
A GEOGRAFICIDADE DA ESCOLA E O ENSINO DE GEOGRAFIA
}

The Geographicity School and the Teachiung of Geography

À Elza Passini

Prof. Dr. Douglas Santos

Professor do departamento de Geografia da Pontifícia Universidade Católica

douglassan@me.com

Artigo recebido em 16/05/2014 e aceito para publicação em 10/06/2014

DOI: 10.12597/tamoios.2014.11626

RESUMO Ensinar Geografia é muito mais que uma simples discussão pedagógica. Partindo da pergunta que nos obriga a identificar "qual seria o significado das disciplinas" ou, em outros termos, "o que disciplinam as disciplinas" escolares, o presente artigo procura identificar o significado de escola e o as razões pelas quais a Geografia continua a ser uma disciplina pertencente à maioria dos currículos. Num diálogo com algumas experiências que desenvolvi tanto no Amapá quanto em Moçambique e, associando a isso, a minha condição de autor de livros didáticos e formador de professores de Geografia, dois aspectos são colocados para o debate: o primeiro deles, referese à condição do discurso geográfico estar associado ao conjunto de relações simbólicas que nos permitem construir as noções básicas de localização e pertencimento e, na sequência, o fato de que a escola também possui uma geograficidade e, portanto, é na tenção relacionada aos lugares (e seus processos) que as identificam que o discurso generalizante da chamada "norma culta" cumpre seu papel geral de dar sentido ao processo civilizatório que pertencemos e insistimos e continuar a construir.

Palavras-chave: ensino de Geografia, escola, identidade, capitalismo, ritos de passagem.

ABSTRACT Teach Geography is much more than a simple pedagogical discussion. Starting of thequestion that in compels to identify "what is the meaning of disciplines" or, in other terms, "what discipline the disciplines" of school, the present article looks for to identify the meaning of school and the reasons for which Geography continues to be one disciplines pertaining to the majority of the curriculum. In a dialogue with some experiences that I developed as far in the Amapá-Brazil as in Mozambique and, associating in that, my condition of author of didactic book and trainer of teachers of Geography, two aspects are put for the debate: the first one of them, refers to the condition of the speech geographic to be associated to the set of symbolic relations that allow us to construct the basic notions of localization and belonging and, in the sequence, the fact of that the school also has a geographicity and, hence, is in the intention related to the places (and its processes) that identify that the generalizing of the called "cultured norm" fulfills your general paper of make sense of the civilizing process that we belong and we insist and continuing to construct.

Keywords: Teaching Geography, school, identity, capitalism, rites of passage. 


\section{CONSIDERAÇÕES INICIAIS}

A literatura sobre o assunto identificado pelo título já está se acumulando sobre as prateleiras e poderia ser resumida nas seguintes proposições:

- O ensino da Geografia, como disciplina escolar para a chamada "escola básica", é um fenômeno originariamente alemão, tem suas raízes no século XVIII e a partir daí se difunde para o restante da Europa.

- Mais que isso, vale lembrar que a escola, enquanto instituição de massas, é um fenômeno da mesma época, e este período também está associado à difusão da ideia de ciência propagada pelo iluminismo, o qual, por sua vez, está associado à noção de ciência legada pela tradição copernicana, galileliana, cartesiana e, por fim, newtoniana. (Burtt:1991)

- Para completar o quadro, o Estado Nacional como formato básico da gestão política, nascido como uma invenção do processo de consolidação da burguesia agrária portuguesa, torna-se hegemônico na Europa e, nos dois séculos seguintes, em todo o mundo habitado. (Lefebvre:1986)

Assim, ensinar Geografia é um dos aspectos da consolidação de um certo tipo de geograficidade ${ }^{1}$, bem como a ideia de "ciência" está associada no imaginário da escola básica, às noções de física, biologia e química (tal como são ensinadas), respondendo às necessidades da estrutura produtiva fabril e o modo de vida urbano.

É neste contexto, ainda, que se desenvolveu a ideia de História e língua materna, associadas às nacionalidades (confundindo-se nação com Estado), bem como a matemática como a única língua universal. (Postmann:1984; Thompson:1989)

Estamos, no entanto, no inicio do século XXI. A instituição escola se consolidou e movimenta, todos os dias, milhões de pessoas em todo o mundo. Crianças, jovens, professores, adultos responsáveis, além de sistemas de transporte, setores da construção civil, indústria papeleira e editorial e mais uma dezena de especialidades se fundem para que o processo se realize. E.claro! Uma instituição dessas dimensões, reunindo em suas salas e pelo seu discurso todas as manifestações religiosas e linguísticas conhecidas e se tornando parâmetro para o reconhecimento do grau comparativo de desenvolvimento dos povos (p. ex. O IDH), tornou-se, também, alvo de muitas críticas, sendo denunciada como parâmetro comum para o quase infinitamente diverso, como suporte de políticas assistencialistas, fonte de manipulação ideológica e, fundamentalmente, a instituição por excelência da realização do modo de viver da sociedade capitalista: a escola é a responsável pela educação (isso todos sabemos), mas não por qualquer educação, considerando que ela não se confunde com a família, nem com as igrejas, nem com as relações de vizinhança. Trata-se, estruturalmente, do processo de urbanização, no sentido que a vida nas cidades se confundiu com o significado de "Urbe" e que esta deixou de ser, simplesmente, o locus do poder político e das relações mercantis, para a estes se somar o fundamento lógico e operacional do processo produtivo: a fábrica (vide, principalmente, Lefebvre: 1972, 1976, 1983, 2013). Eis aqui o fundamento desse pequeno artigo: identificar a escola como a instituição onde acessamos os fundamentos lógicos da sociedade capitalista, em que esta nos é apresentada pelo seu complexo jogo simbólico e, por fim, reconhecer o ensino da Geografia como co-partícipe do processo. A escola é onde vivemos nosso "rito de passagem" de forma mais sistemática e, seus professores (bem como os livros, os mapas, as salas de aula e todos os seus disciplinamentos),são os substitutos contemporâneos dos "velhos da tribo". (Santos: 2008) 


\section{COMENTÁRIOS EM TORNO DE EXPERIÊNCIAS AMAZÔNICAS E AFRICANAS.}

Este subtítulo é, evidentemente, pretencioso. Minhas experiências não ultrapassaram muito os limites do Estado do Amapá e de algumas outras que continuam a ser desenvolvidas junto à Universidade Pedagógica de Moçambique, em cursos de pós graduação, tanto na área de currículo quanto na de ensino de Geografia. Trata-se, portanto, de um certo tipo de "jogo escalar" que costumamos fazer para "enganar o leitor" sem, no entanto, falar uma mentira. Acontece, como o leitor poderá observar, que as tais experiências que vou relatar, envolvem professores que foram meus alunos ou, ainda, que comigo trabalharam no Amapá ou em Moçambique e, portanto, a escala de observação mostra-se obviamente confusa. Certamente que a ideia de Amazônia ou de África é exagerada para qualquer texto ou observador e fiquem, portanto, os topônimos sob suspeição.

Quando iniciei meu trabalho junto à UP (Universidade Pedagógica de Moçambique), nos idos de 2004, tive um aluno (Cândido JasseCanda, era seu nome) que se dedicou a pesquisar as relações entre os ritos de passagem (fundamentais para a sobrevida das relações tribais) e a escola. Li seu trabalho porque fiz parte de sua banca e, dessa maneira, pude aproveitar a leitura para conversar com o autor do texto (CANDA, 2006).

Ali (naquele texto e na nossa conversa) ele terminou de me contar sua História. Eu já sabia que ele tinha sido guerrilheiro da FRELIMO e que havia deixado de lado o caminho de outros companheiros que tinham se tornado funcionários de confiança do Estado moçambicano. Canda tinha se tornado um professor e, num primeiro momento, confiando nas palavras de SamoraMachel, lutou contra as tradições tribais e, agora, perplexo, via que as ordens do governo apontavam para a garantia de sobrevida cultural das mesmas tribos contra as quais ele se postou. Sua dissertação era, portanto, uma espécie de acerto de contas.

Nela ele nos conta que os garotos, quando chegam na puberdade, são levados pelos adultos a acampar longe de suas aldeias e lá permanecem durante toda as férias de verão. Trata-se, na verdade, de uma redução do tempo tradicional, negociado com as instituições de Estado e, agora, se encaixando no entremeio das férias escolares. No acampamento os jovens ouvem histórias, aprendem sobre suas origens e refletem sobre seus valores. Lá também passam frio e fome, devem se dispor a ajudar aos seus companheiros, a fazer sua comida, a caçar e garantir o que sua tribo considera como fundamental para a vida. Ao final são rebatizados, mudam de nome, tornam-se adultos.

Terminado o processo voltam para a aldeia, orgulhosos do novo nome e da nova condição e têm de voltar para a escola. O primeiro choque vai ocorrer logo nos primeiros minutos da primeira aula: o professor faz a chamada e chama em alto e bom som o nome que já não existe mais. Obviamente o garoto não responde, não quer voltar a ser criança... mas o Estado não aceita a mudança e, no mínimo, começa a identificar o aluno como faltante ${ }^{3}$.

Algum tempo depois da defesa de Canda encontrei-me em São Paulo com Hildizina Norberto Dias, naquele momento dando seus primeiros passos no pós doutorado que iria desenvolver na PUC-SP. Lembro-me que naquela conversa Hildizina me fez uma pergunta carregada de justificativas: É possível se aprender no silêncio? E completou: vocês aqui da PUC-SP vão a Moçambique e insistem, a partir dos ensinamentos de Paulo Freire, que a aprendizagem deve se dar a partir da dialogicidade. Professor e alunos devem dialogar para que os saberes disponibilizados pela escola sejam carregados de significados. Então? É possível aprender no silêncio? Claro que é! Respondi depois de alguns segundos difíceis. Quando estou lendo, por exemplo, o diálogo que empreendo não obtém resposta direta do autor do texto. Trata-se de um gesto aparentemente silencioso, onde tudo se processa em minha cabeça. Tanto as perguntas quanto as prováveis respostas. Mas... qual é o sentido 
dessa pergunta?

Hildizina, então, me conta que em uma parcela considerável das escolas moçambicanas, os primeiros anos são constituídos por alunos que provêm de diferentes aldeias, com diferentes identidades linguísticas. Muitos não conseguem compreender o que alguns colegas de classe falam e, certamente, nunca falaram sequer um palavra em português. Acontece que caberá ao professor alfabetizar a todos numa única língua (justamente aquela que é desconhecida de todos) e tal esforço é, de fato, grandioso. Assim, depois derealçar que tais práticas não são indicadas pelas políticas de Estado, mas fazem parte das tradições escolares, muitos professores fazem com que seus alunos permaneçam até 20 minutos segurando os lábios, para que aprendam a ficar em silêncio, condição sine-qua-non para alfabetizar a todos em português. Aí repete a pergunta: É possível se aprender no silêncio? E, se bem me lembro, fiquei em silêncio. Creio que estava tentando apreender o significado de tudo aquilo.

Minhas experiência em Moçambique, além dos elementos práticos e conceituais extremamente específicos, me permitiram retomar um amplo conjunto de reflexões que me tinha sido colocado quando coordenei um grupo de consultores, em nome da PUC-SP, no esforço que, entre 1999 e 2002 o governo do Amapá empreendeu em busca de um novo currículo. Trata-se de uma História algo confusa que poderá ser resumida da seguinte maneira: naquela época o governador do Estado do Amapá (João Capiberibe) assumiu como bandeira geral de seu governo a noção de desenvolvimento sustentável. Já no seu segundo mandato, Capiberibe percebeu que a inexistência de uma política educacional clara que garantisse sua bandeira, poderia levá-lo a uma triste derrota nas eleições seguintes e, com tal preocupação, procura nas universidade brasileiras alguém que possa ajudar seu governo a implantar uma política escolar que tivesse o desenvolvimentos sustentável como parâmetro.

Tal demanda chegou à PUC (mais precisamente ao Instituto de Estudos Especiais) e foi nesse contexto que fui chamado a montar um projeto que desse conta daquelas necessidades.

Meu ponto de partida, aparentemente simples, reivindicava uma revolução geral em toda a tradição disponível. Até aí eu sabia. O que eu ainda iria aprender é que tal condição tornaria todo o esforço mais um fracasso da relação entre a academia e as máquinas de estado. Minha proposta era focar todo o processo escolar na cartografia e com ela parametrizar as noções de reconhecimento e pertencimento necessárias ao desenvolvimento sustentável em plena Amazônia ${ }^{4}$.

No rastro dessa proposição ficamos três anos alocados no Amapá e acabamos constituindo uma equipe de trabalho com mais de 130 professores $^{5}$. Foram cursos e mais cursos, reuniões e mais reuniões, conflitos de todos os tipos e um final melancólico comandado pelos ecologistas envolvidos diretamente com o governo Capiberibe.

Das lições mais importantes poderia afirmar que três delas não podem, jamais, ser deixadas de lado:

1. A primeira, de fundamento político, é a que nos ensina sobre o caráter ambíguo do Estado e o fato dessa instituição sintetizar, dia após dia, um quase infinito conjunto de correlações de força, onde interesses dos mais diversos criam um evidente afastamento entre a lógica acadêmica, a do movimento popular e a daqueles que representam os diferentes tipos de elites que flutuam em torno da noção de poder.

2. A segunda, de caráter geográfico, é a que nos ensina sobre a discrepância entre os objetivos fundamentais da educação escolar (enquanto instituição básica da construção e manutenção da urbe 
capitalista) e os conflitos que tal fato provoca ao exigir o enquadramento de professores, alunos, conteúdos, familiares e, até, dos organismos de gestão;

3. Por fim, a terceira, que nos ensina a identificar a profunda articulação transdiciplinária da escola (sua verdadeira disciplina) que, num aparente paradoxo, se realiza no formato de uma grande variedade de disciplinas específicas.

Explicitar cada uma dessas lições é tarefa para muitas e muitas páginas e não se adequaria aos parâmetros propostos para este artigo. O caminho terá de ser mais curto e direto e, assim, cada uma dessas lições terão de ser tratadas sem grandes demonstrações, para além da pura e simples explicitação de seus possíveis significados e desdobramentos práticos. Para tanto farei o percurso contrário, isto é, iniciarei pela lição três e terminarei na um.

\section{A LIÇÃO NÚMERO TRÊS}

Vejamos: Todas as nossas disciplinas possuem suas raízes na maneira pela qual a chamada "sociedade ocidental" (a qual, em outras palavras, não é mais que o conjunto de povos que possuem suas culturas atreladas diretamente às tradições culturais da Europa ocidental - o que significa, a princípio, línguas latinas e anglosaxônicas, religiosidade associada ao cristianismo e fundamentos produtivos fortemente imbricados na dinâmica capitalista $^{6}$ ). Os elementos mais estruturantes estão diretamente vinculados à tradição grega clássica (principalmente quando nos referimos ao ensino da gramática e da aritmética) enquanto as demais se desdobraram da revolução científica promovida pelo capitalismo mercantil - a partir do século XIII - e que tem em figuras como Copérnico, Galileu e Descartes seus nomes mais proeminentes. Vale lembrar, ainda, que o esforço desses gênios da construção da nossa sociedade teve todos os seus movimentos desdobrados de um tenso diálogo com que conseguiram sistematizar a tradição clássica grega no interior das necessidades da sociedade mercantil nascente.

Tendo como parâmetro as proposições newtonianas para o significado de Natureza, que se consolidaram como o significado geral de Ciência (e, portanto, como o ferramental ideológico na identificação do que não seria científico), nomes como Kant, Humboldt, Darwin, Marx, Mendel entre tantos e tantos outros vão deixando suas marcas ao nos ajudarem a entender o onde estamos e o que somos enquanto co-partícipes da sociedade capitalista, hodiernamente fundada no trabalho fabril, organizada na forma de cidades, parametrizada pelo que chamamos de cultura urbana e disciplinarizada pela existência e ação de Estado. (Santos:2002)

Para tentar uma síntese, sem levar muito em conta os riscos que elas escondem, podemos dizer que pouco importa que as aulas de português sejam tão diferentes das de química ou de educação física: todas elas se cruzam nos seus próprios fundamentos lógicos e, independentemente da consciência que o professor tenha ou não sobre o fato, todas estão a serviço de tornar as novas gerações as plenipotenciárias das bases culturais que nos permite (e nos obriga a) reproduzir de forma ampliada a sociedade a que pertencemos.

Aqui vale retomar as "lições moçambicanas" e apontar para o fato de que as escolas, no interior da sociedade capitalista, possui os mesmos objetivos dos ritos de iniciação nas sociedades tribais. Trata-se muito mais de um processo de inserção nos parâmetros de nossa civilização que, propriamente, o domínio deste ou daquele conteúdo específico, mesmo que não seja possível termos acesso aos fundamentos lógicos de nossa sociedade sem que estudemos e tenhamos algum domínio dos tais conteúdos (Duarte:2000). Na escola, tal como os mais velhos da tribo, contamos histórias, resgatamos as imagens de nossos antepassados, desenhamos e 
identificamos nossas terras, apontamos quem são os "outros" e apresentamos alguns fundamentos para o desenvolvimento do trabalho necessário à sobrevivência coletiva. E fazemos tudo isso em nome do domínio das relações simbólicas. Se fazemos um trabalho de campo, o fazemos para gerar um relatório; se levamos os alunos ao laboratório, dali deve sair algum texto, algum desenho, a solução de alguma equação. Assim, quando nos deparamos com o verbo trabalhar, não se objetiva que façamos mais que reconhecê-lo como um verbo de primeira conjugação e, portanto, sabermos de antemão como os verbos terminados em "ar" devem ser conjugados. Da mesma maneira aprendemos o significado dos catetos nos padrões geométricos do triângulo retângulo, ou, ainda, a velocidade padrão dos objetos em "queda livre" em nosso planeta. A esteconjunto de saberes se acrescentará o mapa-múndi dos países, a tabela periódica e o disco de Newton.

Vem a tona, portanto, a pergunta que deve ser feita a todo professor: o que você ensina quando ensina os conteúdos de sua disciplina? Ou, como já me referi anteriormente: o que disciplinam as disciplinas? E fique registrado uma tentativa de resposta: as disciplinas (todas) nos fornecem as ferramentas básicas da construção e desenvolvimento do nosso pensamento, isto é, nos oferece o conjunto de símbolos e as regras gerais de suas associações para que possamos transformar o sensório em sensório pensado, a experiência em discurso. Ensinar conteúdos é dispor ao educando a maneira pela qual a sociedade a que ele pertence, pensa e interfere no mundo, em seus diversos aspectos, na diversidade de questões que o viver nos coloca. Trata-se, portanto, de um longo caminho que nos retira dos fundamentos apresentados pela família (lato-senso), que nos ensina a falar, andar, comer, hábitos básicos de higiene e elementos básicos de aritmética (como saber quantos anos temos, ou a contar os dedos da mão), além dos fundamentos éticos e estéticos do grupo, para nos colocar na condição de pertencer a um país e à humanidade, falar e escrever de maneira a ser entendido pela totalidade da população identificada pela mesma língua, conseguir desenvolver hábitos de dominar relações simbólicas que nos permita “falar” com o mundo (como no caso da matemática). Trata-se de um mergulho de caráter escalar. Se existe uma imagem mitológica que me faz lembrar a escola é o ato da mãe de Aquiles em mergulhá-lo, ainda criança, na lagoa Estigia tornando-o imortal. O problema é que Tétis (a mãe) tinha de segurá-lo por algum lugar, e o mergulhou sustentado pelo calcanhar, ponto em que o herói ficou vulnerável e por onde acabou recebendo uma flecha envenenada.

É assim que podemos entender o porque aprendemos a aceleração da gravidade em queda livre (algo que não existe), que aprendemos a manipular números (algo que também não existe) ou figuras geométricas (idem) e mapas-múndi (o mundo não é plano e é impossível, na prática, enxergá-lo como aparece num mapa). Ponto por ponto vamos nos apropriando das ordenações simbólicas e, com elas e suas lógicas, olhamos para o mundo real e tentamos compreendê-lo. É aí que se encontra o calcanhar do filho de Tetis: não há, para nós, relação possível com o mundo sem o domínio dos discursos e suas ordenações, mas, os discursos são somente um aspecto do mundo, a maneira como o enxergamos e o organizamos em nossos pensamentos. Como diz GezaSzamozi, a palavra água não molha.(Szamozi:1998)

\section{A LIÇÃO NÚMERO DOIS}

Vamos à lição número dois, aquela de fundamento geográfico.

Uma das primeiras lições que temos de aprender quando nos dedicamos a refletir sobre a Geografia da sociedade capitalista é aquela que nos mostra a dinâmica territorial do seu caráter cumulativo. Explicando 
melhor: a sociedade capitalista tem por fundamento a necessidade de produzir e acumular riquezas (trata-se da noção básica de progresso ou desenvolvimento). No período mercantil, tal processo se realiza pela chamada expansão marítima, que, de marítima só tinha as rotas, pois o objetivo era ampliar o domínio sobre terras emersas. Vamos identificar esse tipo de expansão com a imagem da horizontalidade.

$\mathrm{Na}$ fase fabril, a expansão horizontal continua, mas se inicia um intenso processo de concentração territorial das bases produtivas e, com isso, a expansão das cidades e da urbanização. Trata-se de uma expansão de caráter vertical. (Diamond:2002)

Nos dias de hoje, horizontalidade e verticalidade se interdeterminam. Assim, a expansão da produção agropecuária, por exemplo, não é necessariamente o resultado de maiores áreas de plantio ou criação. A presença da maquinaria e das formas fabris de divisão técnica do trabalho, urbaniza o campo e amplia a produção ampliando a produtividade (esse é um dos parâmetros da chamada revolução verde que, ao mesmo tempo que amplia exponencialmente a produção, vai simplificando os processos, reduzindo, inclusive, a variedade de espécies disponíveis para o consumo)

Um segundo aspecto dessas relações de caráter horizontal e vertical é que a expansão capitalista assimilou a quase totalidade dos povos e, com isso, a imensa diversidade de culturas e economias.

Num primeiro momento, tal assimilação se deu "na boca dos portos" e não exigiu mudanças drásticas no comportamento e identidade dos povos (salvo para aqueles que foram deslocados para o trabalho escravo). Com a verticalização e, portanto, com as mudanças radicais do processo produtivo, os ecossistemas "descobertos" foram sendo destruídos, tornando-se campos de cultivo, e seus habitantes foram transformados em escravos, servos ou, no limite, assalariados. O século XX nos brindou com a presença das cidades proletárias e, com a reordenação dos tecidos urbanos para dar sentido e possibilidade de consumo, deslocamento, produção e realização das relações capitalistas.

Assim, chegamos aos princípios do século XXI com mais de 50\% da população mundial vivendo em cidades. Mas, viver nas cidades e viver as relações urbanas exigidas pelo capitalismo não é, exatamente, a mesma coisa. Desde o inicio do século XVIII os alemães já haviam percebido isso e foram criando a chamada “escola pública”, dirigida às novas gerações proletárias e sua necessária urbanização. O mesmo vai ocorrendo com a França e a Inglaterra e a escola vai se tornando, paulatinamente, uma das principais instituições do "esforço civilizatório" capitalista. Trata-se de construir uma nova sociedade: nova para o feudalismo europeu, para o tribalismo existente nos territórios conquistados e colonizados e igualmente nova para os impérios asiáticos.

Ocorre, no entanto, que quem vai construir, difundir e consolidar o sistema escolar ou é o colonizador ou, na sua ausência, a população autóctone, cuja relação com os fundamentos lógicos da sociedade criada pelos europeus nem sempre estão suficientemente amadurecidas.

O caso do Brasil merece especial atenção pela sua complexidade. A escola pública de massas é um fenômeno que toma seu maior vulto a partir dos anos 60 do século XX. Isso ocorre porque o Estado precisa garantir que as massas que migram do campo para a cidade possam se colocar a serviço da lógica urbana. Assim, as escolas se multiplicam, os sistemas de suplência se tornam mais comuns,os livros didáticos se massificam (se tornam cada vez mais parecidos com revistas de entretenimento) e a ditadura militar vai criar mecanismos de reprodução em massa de professores (licenciaturas curtas). Ocorre, no entanto, que tal massificação tornará a profissão de professor uma alternativa para as primeiras gerações urbanizadas de migrantes, os quais, no interior 
das chamadas redes públicas, se tornarão os professores dos filhos, netos e bisnetos desse mesmo processo.

No caso brasileiro, a massificação das escolas permitiu a rápida depreciação salarial e a deslegitimação profissional do educador, tornando falsamente o problema escolar uma questão de ordem meramente pedagógica, retira das escolas a autonomia sobre seus projetos e processos e torna o Estado o único avalista do significado de saber. Assim, nasce o Enade, o PNLD, o ENEM e tantas outras formas de vigilância, avaliação e desautonomização das escolas. Assim, esconde o processo de redefiniçãa geográfica das pessoas, suas culturas e as instituições que procuram representar e fazer existir.

O caso de Moçambique é outro exemplo interessante. Com o fim do domínio português, observou-se a fuga generalizada dos professores "brancos" e o esvaziamento rápido da capacidade de funcionamento das escolas. Para impedir o sucateamento geral do sistema escolar, o estado socialista convoca estudantes para se tornarem professores das classes precedentes (por exemplo, os alunos da sétima série, podiam se tornam professores da sexta, e assim por diante).

É nesse contexto que nasce a Universidade Pedagógica de Moçambique, cujo objetivo fundamental é formar professores que possam garantir o funcionamento de suas escolas. Mas... escolas para que? Justamente para poder participar do mundo que para lá foi levado pelos portugueses, só que agora sob a gestão dos próprios moçambicanos.

As dificuldades são imensas. Trata-se de fazer existir um sistema escolar em meio a tradições culturais onde tal instituição é, a princípio, inexistente. É, tal como nas aldeias indígenas no Brasil, a ruptura com a tradição oral, o refazer das histórias, dos heróis, dos sistemas de localização e pertencimento (uma das funções básicas da escola em Moçambique é colaborar na constituição da moçambicanidade, pois, num pais plurinacional, multilinguístico, com parcela significativa da população vivendo sob a égide das relações tribais, sentir-se moçambicano é a condição de uma minoria), e, portanto, a instituição da ruptura, aquela que vem para afirmar que os saberes dos povos são, na verdade, ignorâncias, pois o verdadeiro saber está definido no interior da lógica criada e desenvolvida na Europa ocidental.

É nesse contexto que parcela significativa dos professores não possui um dos hábitos mais próximos da urbe capitalista: o da leitura sistemática e, portanto, desconhece a prática e o significado do jogo simbólico que tem a responsabilidade de ensinar para as novas gerações. É este o contexto que nos leva a imaginar que o processo de consolidação da sociedade capitalista, tanto na sua horizontalidade como verticalidade, estão distantes de terem terminado. A presença da chamada "norma culta" como referencial escolar é o ponto de inflexão que nos permite identificar as tais das escolas "boas" em contraposição às escolas "fracas". Trata-se, de fato, da contradição entre uma sociedade ideal (onde todos saberiam de tudo, consumiriam as mesmas coisas e seriam felizes) com a sociedade real, que cria e recria diferenças a cada dia e lugar, inclusive no que se refere ao significado de saber ou de ciência.

\section{A LIÇÃO NÚMERO UM}

Quanto à primeira lição (a presença do Estado e suas ambiguidades) é preciso considerarmos que não será possível desenvolver aqui uma teoria geral de Estado e, por isso mesmo, vamos nos dedicar somente a sua relação com o sistema escolar e os processos de ensino-aprendizagem.

Retomando as observações sobre o surgimento da "escola de massas" (a partir de meados do século 
XVIII) e a necessária re-educação para se aprofundar e garantir o "modo de vida" da nascente sociedade capitalista de base urbano-industrial, mais um aspecto a se realçar é que tanto do ponto de vista das elites (principalmente aqueles setores vinculados ao que ainda restava - e era muito - das relações feudais) quanto da população trabalhadora, a ideia de país era algo relativamente estranho. Tal como hoje na maior parte dos países africanos, nos quais as escolas possuem a gigantesca tarefa de promover o desmonte das relações tribais e vincular a todos aos valores e dinâmicas de um único Estado-nação, do transcorrer dos séculos XVIII até os dias de hoje, seja no desmonte das identidades clânicas ou de aldeia, seja na pasteurização das diferenças culturais advindas dos processos migratórios ${ }^{7}$, seja no convencimento da existência de uma identidade necessária para além das nações (vide o caso típico da Espanha e as lutas bascas, galegas e catalãs e vale, ainda, acompanhar o desenrolar dos processos de fragmentação dos países do leste europeu), a escola continua sua cruzada original de identificar como unidade necessária o resultado dos confrontos cotidianos de todos os que compõem os Estados nacionais, seja na escala interna, seja na escala planetária.

\section{UM SIGNIFICADO PARA O ENSINO DA GEOGRAFIA}

Nas últimas décadas, tal como a literatura que identifica as origens da Geografia como disciplina escolar (e, depois, acadêmica), as tentativas de identificar um significado para nossa disciplina também estão se acumulando pelas prateleiras. Num repasse rápido, lembremos que enquanto Lacoste nos informava que a Geografia serviria, antes de mais nada, para fazer a guerra e Moreira respondia informando que ela deveria servir para desvendar máscaras sociais, enquanto Milton Santos nos propunha uma Geografia Nova e considerava que, para todos os efeitos, devíamos nos concentrar na ideia de que estudamos o espaço e, portanto, é o espaço o objeto de nossos sujeitos, criamos, no Brasil, base suficiente para produzir uma extensa bibliografia sobre o assunto. Vale lembrar que ela, felizmente, continua sendo produzida, e nossas dúvidas vão se aprofundando e tomando formas cada vez mais consistentes.

Acontece, no entanto, que tais debates chegaram nas escolas, parafraseando Marx, primeiramente como tragédia e agora como farsa. Lembremos (e os que viveram, no transcorrer dos anos 70, o interior das discussões sobre escolaridade em nosso país certamente lembrarão) que terminamos nossas relações com a ditadura militar ${ }^{8}$ num efetivo combate contra a chamada "licenciatura curta" e iniciamos o período que agora chamamos de "democrático" participando das grandes reformas curriculares ocorridas em praticamente todos os estados brasileiros e, delas, se desdobraram os embates para uma nova LDB (esforço do movimento sindical dos professores que acabou derrotado pelos intelectuais que se tornaram funcionários de Estado, como Fernando Henrique Cardoso e Darcy Ribeiro) e, na lógica dessa relação vieram os Parâmetros Curriculares (com os mais diversos títulos e para todos os níveis e modalidades de ensino) montando a passagem da tragédia para a tragicomédia atual.

O ensino de Geografia, evidentemente, não ficou imune a tudo isso. Em nome do que chamamos de "Geografia Crítica" "9" novas propostas foram chegando às escolas e, na maioria daquelas que acompanhei, percebeu-se muito mais o desespero que a esperança. Vale lembrar a perplexidade dos professores do ensino fundamental do Estado de São Paulo, quando, ao receberem a nova proposta curricular, foram informados que deveriam ensinar o significado de "Modo de Produção" para os alunos da então $5^{\text {a }}$. Série (atual 6 ${ }^{\circ}$. ano). Levando em conta que a maior parte desses professores nunca tinham ouvido falar de tal categoria em seu processo de 
formação acrescentemos que a proposta curricular, ao articular temas, em nenhum momento explicitou que tipo de prática escolar poderia realizar o que o novo currículo propunha em nome da tal Geografia Crítica.

Este, sem dúvida, foi o momento da tragédia e esta, com maior ou menor grau, foi se reproduzindo pelo país. Participei de debates no Rio Grande do Sul, Paraná, Goiás, Rio de Janeiro, Pará, Pernambuco e Bahia ${ }^{10}$, além de São Paulo, evidentemente. O que ocorreu nas duas décadas seguintes é, sem dúvida, o desdobramento de esforços que, por vezes em paralelo, por vezes em direções opostas, a prática escolar e a máquina disciplinarizadora do Estado está construindo nos dias de hoje ${ }^{11}$.

É, a princípio, no interior dessa prática política carregada de ambiguidades e de um sistema escolar estruturalmente desigual, que a geograficidade das escolas vai realizando a efetiva prática de se construir e difundir um discurso geográfico.

É, justamente, em meio às discussões sobre qual seria o objeto da Geografia, se ela seria crítica ou não, se somos de esquerda ou de direita (ou de centro, como alguns parecem se sentir mais confortáveis), que temos de resgatar o que existe de mais tradicional, de mais básico e, com isso, retomarmos o debate com os professores, com as escolas, com sua desigual distribuição tanto no que se refere aos números, quanto às suas singulares identidades e, voltando ao ponto, às suas especificidades geográficas.

Enquanto a chamada "norma culta" procura a homogeneização e pasteurização dos fundamentos lógicos do conhecimento e, portanto, das identidades e suas redes escalares de pertencimento, é preciso que se reconheça os diversos parâmetros culturais, políticos, econômicos, civilizatórios, enfim, que leem tais normas e as traduzem para suas especificidades. Enfim:

- é preciso reconhecer que cada saber é um saber e que a norma culta é somente um entre tantos, com a condição de, nesse momento da nossa História, postular-se como hegemônico, definir-se como o saber que ordena e realiza do nosso modo de vida (no dizer dos geógrafos);

- mais que isso, é preciso reconhecer que a Geografia é uma entre tantas disciplinas escolares e que ela desempenha seu papel na relação com as demais e, portanto, que pensar o ensino da Geografia sem pensar a escola é pensar o objeto sem identificar seus objetivos;

- Por fim, é preciso reconhecer que, desde seus mais longínquos movimentos até sua inserção como disciplina escolar, cabe à Geografia ordenar nossas articulações simbólicas (no sentido que possui o que entendemos por lógica), em busca do reconhecimentos dos lugares e da delimitação do significado de pertencimento. Trata-se, portanto, de um embate que ultrapassa em muito o significado de pedagogia, e que aponta para o reconhecimento das diferentes epistemologias que compõem a totalidade dos saberes humanos e tal reconhecimento, antes de tudo, é uma postura política. 


\section{NOTAS}

1 - Entende-se por geograficidade a condição dada ao caráter distributivo do fenomênico, na sua diferencialidade e na escala do ecúmeno humano, de ser fator de interdeterminação. Não estou me referindo, portanto, à maneira pela qual Dardel (2011) se refere ao tema.

2 - Vale lembrar que "ler e escrever" bem como o chamado "hábito de leitura", não podem ser considerados como valores universais e atemporais. Trata-se, junto com tantos outros, do conjunto de saberes que viabiliza o existir do nosso modo de vida atual.

3 - Sempre me volta à memória uma aula em que eu perguntava para os alunos: Se a escola se organiza pela necessidade de disponibilizar os conhecimentos contidos nas disciplinas, o que, no final das contas, disciplinam as disciplinas? Em meio ao debate Canda nos conta que, ainda pequeno, chegou na escola com alguns minutos de atraso e, vendo o portão aberto, considerou que poderia entrar sem que ninguém o visse. Acontece que, do outro lado o esperava o temível jesuíta que tomava conta da escola. Agarrado pela camisa, Canda se lembra de sentir seus pés acima do chão e, com regularidade, a dor que vinha da vara que o sacerdote usava para surra-lo, enquanto, com a voz calma de quem cumpre seu dever, vai repetindo na forma de um mantra, que um dia Canda lhe agradeceria pelo castigo pois, naquele momento, estava sendo libertado dos últimos resquícios de selvageria que ainda habitavam seu corpo. Essa história me persegue desde então.

4 - As bases teórico metodológicas do projeto estão publicadas num longo artigo que escrevi para a revista Construção Psicopedagógica (Santos:2008).

5.-.Edson Martins, em sua dissertação de mestrado, nos conta alguns detalhes desse processo.

6.-.Vale lembrar que a escola, no formato que a conhecemos, é uma invenção dessa mesma sociedade ocidental e sua implantação no interior das mais diferentes tradições culturais pouco ou nada as respeita, principalmente quando se trata do ensino das linguagens básicas da técnica (como a matemática, p. ex.) e da associação entre esta e a noção ocidental iluminista de ciência (como no caso da física, química e biologia). O ensino das línguas maternas está profundamente imbricado com o ensino das gramáticas e, portanto, no esvaziamento do significado da mensagem em nome da reificação do significado da lógica formal. Podemos afirmar que hoje, na maior parte do continente africano e na indonésia, a escola dá continuidade ao processo colonial sem a incômoda presença de tropas estrangeiras.

7.-.Vale assistir o filme "Entre os Muros da Escola" - Com título original em francês "Entre lesmurs" e dirigido por Laurent Cantet, o filme foi vencedor do festival de Cannes de 2008.

8.-.Militar por que se tratou da leitura que a caserna tinha da chamada sociedade civil. Mas, isso é assunto para outro artigo.

9.-. Não confundir a expressão que identificava o movimento político de geógrafos de esquerda contra os fundamentos geográficos que davam sustentação ao que entendíamos por direita, com algum título de livros didáticos.

10 - Na Bahia o processo foi particularmente interessante. A secretaria de educação do estado resolveu adotar para todas as escolas uma coleção de livros em que eu era um dos autores e, eu e meus companheiros, nos dispusemos a debater com os professores sobre o uso do material. Creio que foi com essa experiência que conseguimos compreender o quanto a escola é capaz de resistir ao que não conhece.

11 - Quando pensamos no ensino de geografia um exemplo ainda percorre a comunidade internética: a secretaria de educação do Estado de São Paulo, retirou do currículo dos primeiros anos do ensino fundamental o ensino das disciplinas que tratam diretamente do fenomênico (geografia, história e ciências) e reduziu o processo de formação ao ensino de Português e Matemática. Em torno de 30 anos depois de derrotar as licenciaturas curtas o que se vê é a pura e simples eliminação de conteúdos na formação básica de nossos alunos. 


\section{BIBLIOGRAFIA}

ARISTÓTELES. Organon. Lisboa: Guimarães Ed., 1985.

BACHELARD, Gaston. A Poética do Espaço. São Paulo: Martins Fontes, 1993.

BERMAN, Marshall. Tudo que é Sólido Desmancha no Ar. São Paulo: Companhia das Letras, 1987.

BLOCH, Ernst. Sujeto-objeto - El Pensamiento de Hegel. México: Ed. Fondo de Cultura Económica, 1985.

BOURDIEU, P. O Poder Simbólico. Lisboa: Difel, 1989.

. Escritos de Educação, Rio de Janeiro, Ed. Vozes, 2002.

BRANCO, J.M.F. Dialética, Ciência e Natureza. Lisboa: Ed. Caminho, 1989.

BURTT, Edwin A. As Bases Metafísicas da Ciência Moderna. Brasília: Ed. UNB, 1991.

CANDA, C. J. Educação autóctone tradicional e a educação oficial moderna: efeitos dos ritos de iniciação autóctone sobre o rendimento escolar dos alunos iniciados. Mimio, Dissertação de Mestrado defendida no Programa de Educação e Currículo - PUC-SP, 2006

DARDEL, E. O Homem e a Terra - natureza da realidade geográfica. São Paulo. Ed. Perspectiva, 2011

DIAMOND, Jared, Armas, Germes e Aço. Rio de Janeiro: Ed. Record, 2002.

DUARTE, Newton, Vigotski e o “Aprender a Aprender”, Campinas, Ed. Autores Associados, 2000.

ENGELS, F. Anti-Düring. Rio de Janeiro: Paz e Terra, 1976. . Dialética da Natureza. Rio de Janeiro: Ed. Leitura, s/d.

FEYERABEND, Paul. Adeus à Razão. Lisboa: Ed. 70, 1991.

FREINET, C. , O Método Natural, três volumes, Lisboa, Editorial Estampa, 1977.

FREINET, C.. As técnicas Freinet da Escola Moderna. Lisboa, Ed. Estampa, 1975.

FREIRE, Paulo: A Importância do Ato de Ler em três artigos que se completam. São Paulo, Ed. Cortez, $29^{a}$ edição 1994.

HARPER, Babette et alli, Cuidado, Escola: Desigualdade, Domesticação e Algumas Saídas. S Paulo, Ed. Brasiliense, $19^{\mathrm{a}}$ ed. 1985.

LEFEBVRE, H. Lógica Formal/ Lógica Dialética. Rio de Janeiro: Ed. Civ. Bras. 1979.

LEFEBVRE, H. Hegel, Marx, Nietzsche. México: Siglo Veintiuno Ed., 1986.

LEFEBVRE, H. O Pensamento Marxista e a Cidade. Lisboa, Póvoa do Varzim, Ed. Ulisseia, 1972

LEFEBVRE, H. La Producción del espacio. Madri, Ed. Capitan Swing, 2013

LEFEBVRE. La Presencia y la Ausencia. México: Ed. Fondo de Cultura Económica, 1983.

LENIN, V. I. Cuadernos Filosóficos. Obras Completas, tomo XLII. México: Akal Editor, s/d.

MARX, K. Manuscritos Económico-Filosóficos. Lisboa: Ed. 70, 1989.

Elementos Fundamentales para la Crítica de La Economía Política. em 3 vols. México: Siglo Veintiuno Ed., s/d.

MOREIRA, Ruy. O Círculo e a Espiral. Rio de Janeiro: Ed. Obra Aberta, 1993.

O Discurso do Avesso. Rio de Janeiro: Ed. Dois Pontos, 1987.

POSTMAN, N. Tecnopólio: a Rendição da Cultura à Tecnologia. São Paulo: Nobel, 1994.

SANTOS, D. Gênesis: Reflexões em torno de uma Espácio-Temporalidade__Primordial. http://arsgeographica.zoomblog.com/archivo/2005/10/28/gnesis-reflexes-em-torno-de-uma-espaci.html , 1995. Conteúdo e Objetivo Pedagógico no Ensino da Geografia. In Caderno Prudentino de Geografia, $\mathrm{n}^{\circ}$ 17. Presidente Prudente. AGB, 1995. 


O Significado de Escola, in Construção Psicopedagógica: disponível em

http://pepsic.bvsalud.org/scielo.php?pid=S1415-69542008000100003\&script=sci_arttext

A Reinvenção do Espaço. São Paulo: Ed. UNESP, 2002.

SZAMOSI, G. Tempo \& Espaço: As Dimensões Gêmeas. Rio de Janeiro: Jorge Zahar Ed., 1988.

THOMPSON, E. P. Tradición, Revuelta y Conciencia de Classe. Barcelona: Ed. Critica, 1989.

A Miséria da Teoria. Rio de Janeiro: Ed. Zahar, 1981.

VIGOTSKI, L. S, Pensamento e Linguagem, São Paulo, Martins Fontes, 1999.

A Formação Social da Mente. São Paulo, Martins Fontes, 1998. 